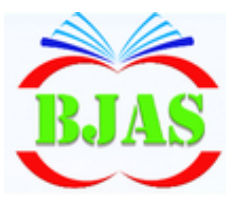

ISSN $1814-5868$
Available online at http://bajas.edu.iq

https://doi.org/10.37077/25200860.2019.198

College of Agriculture, University of Basrah

Basrah J. Agric. Sci., 32(2): 74-84, 2019

\section{Basrah Journal of Agricultural Sciences}

E-ISSN: 2520-0860

\title{
Gel Extraction from Caper Fruits (Capparies spinosa L.) and Assess its Effectiveness as Antioxidants
}

\author{
Anwar R.T. Al-Birawee* \& Amera K. Nasser \\ Department of Animal Production, College of Agriculture, University of Basrah, Iraq. \\ *Corresponding author e-mail: noorraadtalib@gmail.com \\ Received 19 September 2019; Accepted 20 November 2019; Available online 30 December 2019
}

\begin{abstract}
The results of the current study showed that the caper plant contains active compounds such as phenols and flavonoids. Caper gel exhibited the highest antioxidant activity about $92.31 \%$ when used at concentration $100 \%$, when was comparable to that shown by the industrial antioxidant Butylated Hydroxy Toluene (BHT), which reached to 93.41\%. The results also indicated that the alcohol extract of the caper gel was able to sweep the hydrogen peroxide amounted to $81.05 \%$ compared to that shown by the industrial antioxidant and without significant differences. It also showed a reduction of 2.25 $\%$ which was not significantly different from standard ascorbic antioxidant which had the highest average of $2.84 \%$. This ability increased with an increase in gel concentration with no significant differences.
\end{abstract}

Keywords: Antioxidants, Caper fruits (Capparies spinosa), Gel extraction.

\section{Introduction}

Recent studies have pointed to the role of medicinal plants as antioxidants as a substitute for industrial antioxidants, medicines, and chemotherapies (Comai et al., 2007). Recent studies and scientific research have proven the pharmacological effects of many plant compounds in the treatment of many diseases as studies mention the positive role of plants in reducing the incidence of diseases (Kim et al., 2006). Many industrial antioxidants are currently used commercially and largely include Butylated Hydroxy Toluene (BHT) and Butylated Toluene Anisole (BHA). In recent years, there have been many doubts about the safety of these antibiotics because of their negative effects on consumer health, as it is known that industrial antioxidants are dealt with strictly by the US Food and Drug Administration. This is due to concerns about its toxicity above certain limits (Manhiani et al., 2013). Phenolic compounds are the most prominent natural antioxidants. They have the ability to capture free radicals, bind mineral ions and stimulate antioxidants to break down the chain of oxidation reactions. They thus participate in the first line of defense against free radicals (Chaudhary et al., 2010). There are many substances involved in manufacturing and pose a high risk such as sodium nitrate and monosodium glutamate (Khaled, 2006). 
The caper plant was one of the most important plants with a high content of antioxidants and is perennial spiny shrubs grow naturally and bloom fully during the summer (Pascual et al., 2006). Caper is the most common aromatic plants in Mediterranean kitchens, where they are used as a spice (Tesoriere et al., 2007). Therefore, this study aimed to extract the gel from caper plants and detect its active substances, identify its antioxidant potential and its ability to capture free radicals.

\section{Materials \& Methods}

\section{Collect and prepare samples}

The caper fruits were collected from shrubs in July, selected carefully and cleaned of dirt, dried at $40^{\circ} \mathrm{C}$ by oven, the dry fruits were ground using a laboratory mill, put the fruit powder in polyethylene bags, store at $4^{\circ} \mathrm{C}$ until testing.

\section{Gel powder Preparation:}

\section{Fat remove}

The fat was removed from the dried ground of caper fruits by the intermittent extraction by soxhlet (Ashour et al., 2005).

\section{Chemically gel extracting}

Gel extraction according to the method mentioned by Singer et al. (2011) with some modification; Blend caper deodorized powder with distilled water by (1: 40)(w/v). Adjust the $\mathrm{pH}$ to 9 by adding a sodium hydroxide solution at a concentration of $0.5 \mathrm{~N}$. Mix for 30 minutes at room temperature. Put the mixture to a centrifuge under the cooling speed 4500 Revolution for 30 minutes. Adjust the $\mathrm{pH}$ of the filtrate to 4.8 by adding hydrochloric acid $\mathrm{HCl}$ at a concentration of $0.5 \mathrm{~N}$. Place the filter with a centrifuge at a speed of 4500 cycles for 30 minutes at $5^{\circ} \mathrm{C}$.
To increase the precipitation, two volumes of $95 \%(1: 2)(\mathrm{v} / \mathrm{v})$ ethanol were added, the extract was left for 24 hours at $5^{\circ} \mathrm{C}$. Dissolve the precipitate with distilled water and adjust the $\mathrm{pH}$ to 7 by adding a $0.5 \mathrm{~N} \mathrm{NaOH}$ solution. Dry at $40{ }^{\circ} \mathrm{C}$ for 24 hours. Grind the dried gel with a laboratory mill. Keep the dried gel in airtight containers.

\section{Chemical detection of active substances:}

\section{Glycosides test:}

Glycosides were detected using a Benedict reagent, the reagent was prepared by dissolving $173 \mathrm{~g}$ of sodium citrate with $100 \mathrm{~g}$ of anhydrous sodium carbonate with $600 \mathrm{ml}$ distilled water with quiet heating, dissolve $17.3 \mathrm{~g}$ copper sulfate in $150 \mathrm{ml}$ distilled water, mix the two solutions with constant stirring, complete the volume to 1 liter, mix two equal parts of Benedict's reagent and plant extract, leave in a water bath for 10 minutes, the appearance of a red precipitate is indicative of the presence of glycosides according to the method (Yasser, 2011).

\section{Alkaloids test}

Alkaloids were detected according to the method (Harborne, 1984). As follows:

1.Mayer's Reagent: Added 13.5 g $\mathrm{HgCl}_{2}$ mercury chloride and $50 \mathrm{~g}$ potassium iodide to $100 \mathrm{ml}$ distilled water.

2.Wagner's Reagent: Added $100 \mathrm{ml}$ of distilled water to $1.3 \mathrm{~g}$ of iodine and $20 \mathrm{~g}$ of potassium iodide.

3.Margus Reagent: Mix $1 \mathrm{ml}$ of formaldehyde with $10 \mathrm{ml}$ of concentrated sulfuric acid.

Some drops of each reagent were added to $1 \mathrm{ml}$ of alcoholic extract of gel, a yellowpurple precipitate is used when using the Margus reagent, the emergence of turbidity when using Mayer's reagent, the appearance 


\section{Al-Birawee \& Nasser / Basrah J. Agric. Sci., 32 (2): 77-87, 2019}

of a reddish-brown precipitate when using the Wagner's reagent. Indication of the presence of alkaloids.

\section{Phenolic compounds test:}

Phenols were detected using ferric chloride 1 $\%$, Added $1 \mathrm{ml}$ of the solution to $1 \mathrm{ml}$ of plant extract, appearance of green color, an indication of the presence of phenols according to the method (Harborne, 1984).

\section{Tannins test}

Boil $10 \mathrm{~g}$ plant powder with $50 \mathrm{ml}$ distilled water, the solution was filtered, let the filtrate cool down, then divide into two and add to the first $1 \%$ acetate lead and when a precipitate appears, white gelatinous textures indicate the presence of tannins, a solution of $1 \%$ ferrous chloride was added to the second section, the bluish-green color indicates the presence of tannins (Yasser, 2011).

\section{Resins test}

$5 \mathrm{~g}$ of plant powder, added $50 \mathrm{ml}$ of ethyl alcohol, left for two minutes in a water bath, the solution was filtered, $100 \mathrm{ml}$ of $4 \%$ hydrochloric acid distilled water was added to the filtrate, the appearance of turbidity in the solution indicates the presence of resins (Yasser, 2011).

\section{Flavonoids test}

Use of potassium hydroxide $5 \mathrm{~N}$ Ethanolic $\mathrm{KOH}$, added $1 \mathrm{ml}$ of the reagent to $1 \mathrm{ml}$ of alcohol extract, the yellow precipitate is an indication of the presence of flavonoids (AlKhazaraji, 1991).

1. Shinoda's test: Add $1 \mathrm{~cm}^{3}$ of the extract a few drops of concentrated hydrochloric acid, added a small piece of magnesium tape or powder, the color is red indicating the presence of flavonoids.
2. Ferric chloride test: Mix $1 \mathrm{~cm}^{3}$ of the extract with a few drops of neutral $(7.5 \%$ ferric chloride) solution $(\mathrm{pH}=7)$. black or black-red indicating the presence of flavonoids.

3. Zinc-HCl reduction: The appearance of the scarlet color when adding a little zinc powder and a few drops of hydrochloric acid to $1 \mathrm{~cm}^{3}$ of the extract indicates the presence of flavonoids.

4. Lead acetate test: A few drops of the reagent were added to $1 \mathrm{~cm}^{3}$ of the extract. Reddish-Brown color with the presence of a precipitating amount of flavonoids.

5. Sodium hydroxide test: A few drops of sodium hydroxide solution were added to 1 $\mathrm{cm} 3$ of the extract. A yellow color disappears when drops of dilute acid are indicated indicating the presence of flavonoids.

\section{Chemical tests}

Moisture and ash content were estimated according to A.O.A.C (2000). Protein content was determined by the Semi-micro Kjeldahl method as described in A.O.A.C (2000). Carbohydrates were estimated by difference according to A.O.A.C (2000).

\section{Measuring antioxidant effectiveness}

The antioxidant activity was determined using the linoleic acid system according to the method reported by Al-Moussawi \& Al-Halfi (2012). The reaction mixture consists of 4.1 $\mathrm{ml}$ of linoleic acid at a concentration of $2.5 \%$ in ethanol, $4 \mathrm{ml}$ of alcohol extract, $8 \mathrm{ml}$ of 0.05 molar phosphate buffer solution 7 and $3.9 \mathrm{ml}$ distilled water, $1 \mathrm{ml}$ of 80 Tween at a concentration of $0.05 \%$ ethanol, the mixture was incubated at $40^{\circ} \mathrm{C}$ for 24 hours. The degree of oxidation was determined by thiocyanate method, mix $0.1 \mathrm{ml}$ of the 
mixture, added $9.7 \mathrm{ml}$ of $75 \%$ ethanol and 0.1 $\mathrm{ml}$ of ammonium thiocyanate at a concentration of $30 \%$, three minutes later, 0.1 $\mathrm{ml}$ ferrous chloride of 0.02 molar concentration prepared in $3.5 \%$ hydrochloric acid was added.

The absorbance was measured at a wavelength of $500 \mathrm{~nm}$, BHT and tocopherol were used for comparison, the control sample was prepared in the same way above except for mixing $4 \mathrm{ml}$ ethanol instead of plant extract.

The percentage inhibition of linoleic fatty acid peroxides was calculated according to the following formula:

$$
\text { Antioxidant Effectiveness }=\frac{\text { Sample absorbance reading }}{\text { The absorbance reading of the control sample }} \times 100
$$

\section{Measurement of Reducing Power}

Followed the method Osawa \& Namiki. (1981), included mixing $2.5 \mathrm{ml}$ of caper alcohol extract and ascorbic acid, With 2.5 $\mathrm{mM}$ phosphate buffer solution, $\mathrm{pH} 6.6$ and 2.5 $\mathrm{mL}$ of Potassium Ferricyanide solution $1 \%$, incubate the mixture at $50^{\circ} \mathrm{C}$ for 20 minutes, the reaction was then terminated by adding $2.5 \mathrm{ml}$ of Trichloroacetic acid $10 \%$, the centrifugation of the mixture was carried out at a speed of 2000 r.min ${ }^{-1}$ for 10 minutes, separate the top layer of the solution and add $5 \mathrm{ml}$ distilled water and $1 \mathrm{ml}$ of $0.1 \%$ ferric chloride.

The absorbance was measured at a wavelength of $700 \mathrm{~nm}$, the control sample was prepared by adding all the previous materials except the addition of $2.5 \mathrm{ml}$ ethanol instead of the caper alcohol extract, the following formula was applied to calculate the amount of reducing the power of the extract:

$$
\text { Reduction power }=100-\frac{\text { Sample absorbance reading }}{\text { The absorbance reading of the control sample }} \times 100
$$

\section{Scavenging of Hydrogen Peroxide}

The alcoholic extract of caper gel was estimated to Scavenging hydrogen peroxide root according to the method described in Turkoglu et al. (2010), take $1 \mathrm{ml}$ of alcohol extract for caper gel and $0.6 \mathrm{ml}$ of 0.002 molar hydrogen peroxide, prepared in phosphate buffer 0.1 molar at $\mathrm{pH} 7.4$, the samples were then left for 10 minutes at laboratory temperature. The absorbance was measured at a wavelength of $230 \mathrm{~nm}$. The results were compared with BHT. The ability to Scavenging hydrogen peroxide root was calculated according to the following formula:

$=\frac{\text { The absorbance reading of the control sample }- \text { Sample absorbance reading }}{\text { The absorbance reading of the control sample }} \times 100$

\section{Chelating ability of Ferrous ion}

The ability of the caper gel alcohol extract to chelate ferrous ion to the method described in
Gülçın et al. (2003), mixed $0.4 \mathrm{ml}$ of alcoholic extract with $0.4 \mathrm{ml}$ of ferric chloride $2 \mathrm{ml}$ molar with $0.4 \mathrm{ml}$ 8-Hydroxyquinoline at a concentration of 5 molar (ethanol- 
prepared), incubate the mixture for 10 minutes at room temperature in a dark place. The absorbance was measured along a 562 $\mathrm{nm}$ wavelength, the results were compared with EDTA, the control sample was prepared in the same way except for the sample, the ability of the plant extract to chelate ferrous ion was calculated according to the following formula:

$$
\text { Chelating ability of Ferrous ion }=\frac{\text { Sample absorbance reading }}{\text { The absorbance reading of the control sample }} \times 100
$$

\section{Statistical analysis}

Data were analyzed statistically using Complete Randomized Design (CRD), using the statistical software SPSS (SPSS, 2012), the results were compared using the Revised Least Significant Difference (RLSD) at the probability level $p<0.05$ (Al-Rawi \& Khalaf Allah, 2000).

\section{Results \& Discussions}

\section{Chemical composition of caper gel}

Table (1) shows the results of the chemical composition of the local caper gel, which is an estimate of moisture, protein, fat, ash and total carbohydrate levels. The moisture mean was $11.5 \%$, which is close to the humidity found by Hosseni-Parvar et al. (2010) in the basil seed gel which reached $11.57 \%$ and more than the moisture content in the Iranian basil seed gel which reached 5.79 (Razavi et al., 2009). The difference in humidity is due to different extraction and sedimentation methods. The average ash content in the caper gel was $4.5 \%$, which is lower than the ash levels found by Fekri et al. (2008) in quince seed gel and flax gel, which were 8.20 and 5.80, respectively. The fat percentage was $0.35 \%$, which is comparable to the percentage of fat found by Al-Jubouri et al., (2014) in flaxseed gel which was 0.34 and 0.36 for two models (A and $\mathrm{B}$ ) respectively. Protein content in caper gel was $1.4 \%$, which is comparable to the protein content in fenugreek seed gel $1.56 \%$ found by Razavi et al. (2009). The presence of protein at these low levels in the gel is of great importance in activating the process of water absorption (Garti \& Leser, 2001). It also helps in the formation of emulsions and their stability in the food systems and pharmaceutical industries (Dickinson, 2003). The percentage of carbohydrates in the caper gel was $82.75 \%$, which is higher than the proportion of carbohydrates found by AlJubouri et al. (2014) in the flaxseed gel which reached $66.35 \%$. These findings are in agreement with those of Goycoolea \& Caedenas (2003) that gel extracted from plants contain mostly carbohydrates.

Table (1): The chemical composition of the local caper gel

\begin{tabular}{c|c}
\hline Chemical components & $\%$ \\
\hline Moisture & 11.50 \\
\hline Ash & 4.50 \\
\hline Fat & 0.35 \\
\hline Protein & 1.40 \\
\hline Carbohydrates & 82.75 \\
\hline
\end{tabular}




\section{Effective compounds in Caper gel}

The results of the qualitative data revealed that the alcohol extract of caper gel contains most of the active compounds, which included glycosides, alkaloids, phenols, tannins, resins, and flavonoids, all statements have yielded positive results, inferred from the reactions shown in table (2).
These findings were agreed with other studies that have shown that the alcoholic extract of caper plants contains biologically active compounds, which were found in different parts of the caper plant $(\mathrm{Ma} \&$ Zhang, 2017).

Table (2): Detection results of active compounds in alcohol extract for caper gel

\begin{tabular}{c|c|c}
\hline Active compounds & Reagent uses & Regent results \\
\hline Glycosides & Benedict reagent & + \\
\hline Alkaloids & Mayer's Reagent & + \\
\cline { 2 - 3 } & Wagner's Reagent & + \\
\cline { 2 - 3 } & Margus Reagent & + \\
\hline phenols & Ferric chloride & + \\
\hline tannins & Lead Acetate & + \\
\hline Resins & HCl acid & + \\
\hline
\end{tabular}

\section{Measurement of antioxidant activity outside the body}

The results of fig. (1) showed that the alcoholic extract of adult gel possesses antioxidant activity of linoleic acid at different concentrations compared with synthetic antioxidants Butylated Hydroxy Toluene (BHT). It is clear from the figure that the alcoholic extract of the caper gel showed a nearly similar effect to that of the synthetic antioxidant BHT. Caper gel effectiveness was $85.58 \%, 88.55 \%, 92.31 \%$ and $92.47 \%$ when used as $20 \%, 80 \%$ and $100 \%$. Those of BHT was 88.46, 92.47 and $93.41 \%$ respectively. The results of the study also showed that the alcoholic extract of caper gel possesses antioxidant activity that was not significantly different from what the industrial antioxidant BHT showed at a concentration of $100 \%$. This result is encouraging the use of caper gel as a natural antioxidant as an alternative to industrial antioxidants and may be attributed to the high effectiveness of caper gel extract as an antioxidant due to effective compounds (Gunjan et al., 2015). Phenols are the most abundant antioxidants in caper plants, which protect against oxidative damage, have the ability to degraded or capture free radicals or have chelating agents that have the ability to bind the catalytic minerals (Zia-Ul-Haq et al., 2011) 
Al-Birawee \& Nasser / Basrah J. Agric. Sci., 32 (2): 77-87, 2019

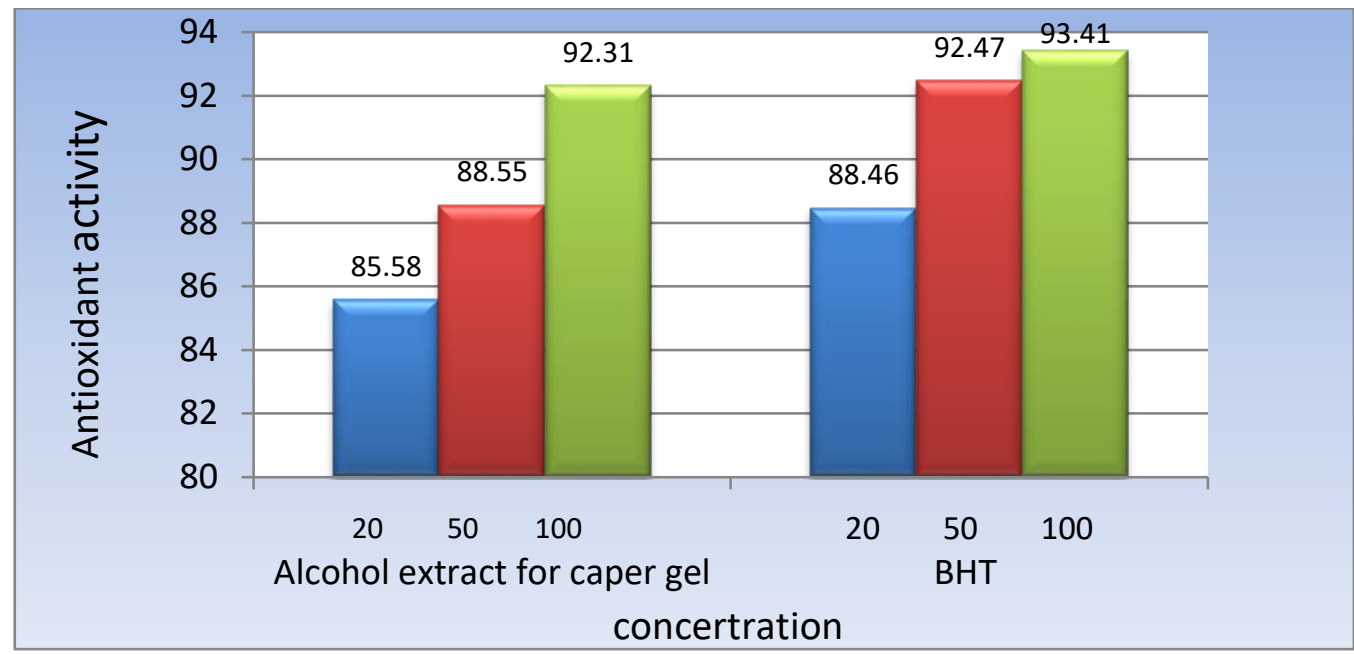

RLSD for concentration $=\mathbf{1 . 2 2}$

Fig (1): Antioxidant activity of alcoholic extract of caper gel.

\section{Reducing strength}

The results of fig. (2) showed the reductive strength of the caper gel alcohol extract compared to the natural antioxidant ascorbic acid, which has the potential to reduce ferric ion $\mathrm{Fe}^{-3}$ in a complex $[\mathrm{KFe}(\mathrm{CN})]$ to the ferrous ion $\mathrm{Fe}^{+2}$ by losing an electron. The results showed that the alcoholic extract of caper gel possesses a significant reductive strength which increased by increasing concentration $(0.66 \%, 1.18 \%$ and $2.25 \%$ when gel concentrations were $20 \%, 50 \%$, and $100 \%$ respectively). The highest reductive strength of caper gel was found to be $2.25 \%$ at $100 \%$ concentration. This approach is comparable to the effect of the standard ascorbic acid $(2.84 \%)$ at the same concentration. The apparent intensity of the color indicates the reductive power of the caper gel alcohol extract to give or release hydrogen ions or increase the hydroxyl root.

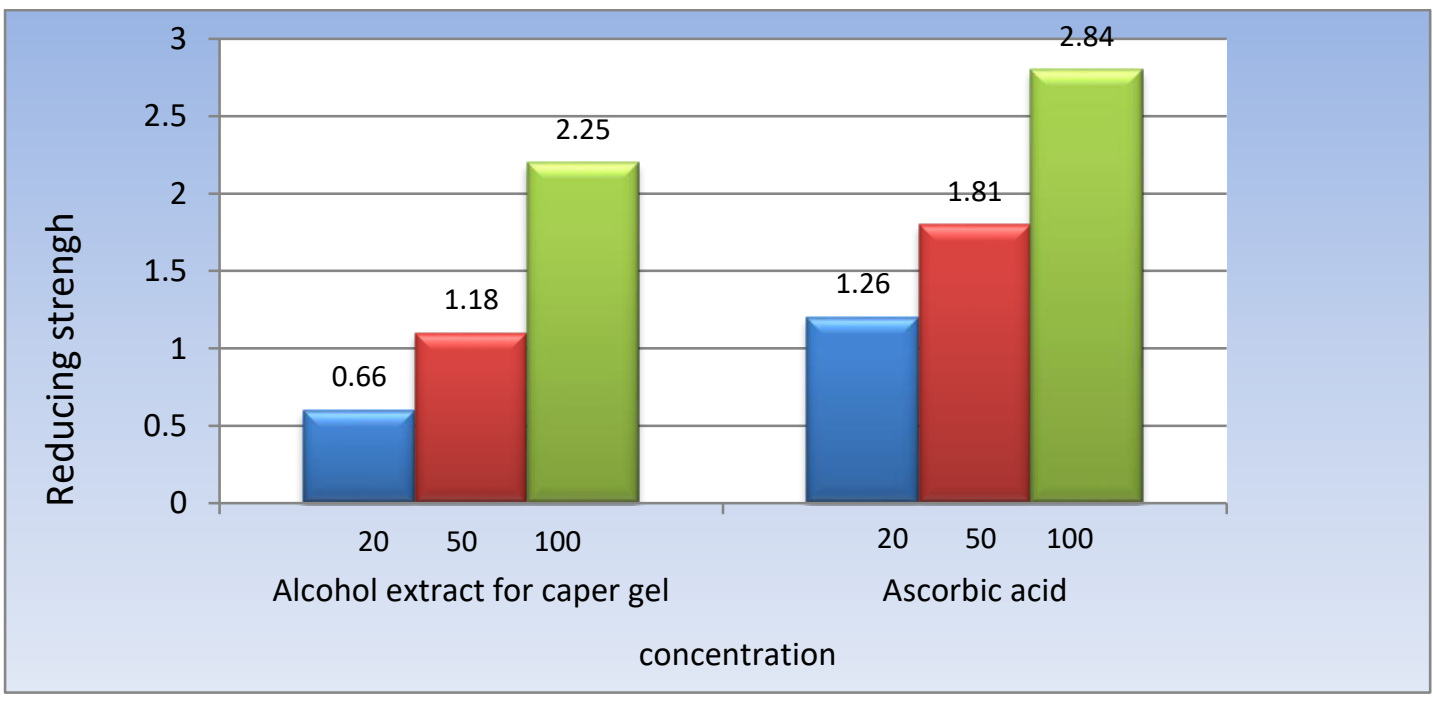

RLSD for concentration $=\mathbf{0 . 5 0}$

Fig. (2): Reducing strength of alcohol extract for caper gel 
Thus, the reduction of reductive power, which is a significant indicator reflecting the antioxidant activity, as well as the number and location of hydroxyl has a role in increasing the reduction force and thus increasing the antioxidant activity.

\section{Scavenging hydrogen peroxide}

The caper gel was able to scavenge hydrogen peroxide significantly $(\mathrm{P}<0.05)$ compared to the industrial antioxidant BHT, the averages for caper gel extract were $72.6 \%, 75.28 \%$ and $81.05 \%$ for concentrations of $20 \%, 50$
$\%$, and $100 \%$ respectively (Fig. 3). However, explained there were no significant differences between the alcoholic extract and the BHT at $50 \%$ concentration (75.28 and 76.7 respectively).The ability of the caper gel alcohol extract to scavenging hydrogen peroxide may be due to active compounds. The active compounds in caper protect cellular systems from the toxic hydrogen peroxide compound, penetrate cell membranes, the process of active compounds was the scavenging of hydrogen peroxide (Bhaduri, 2016).

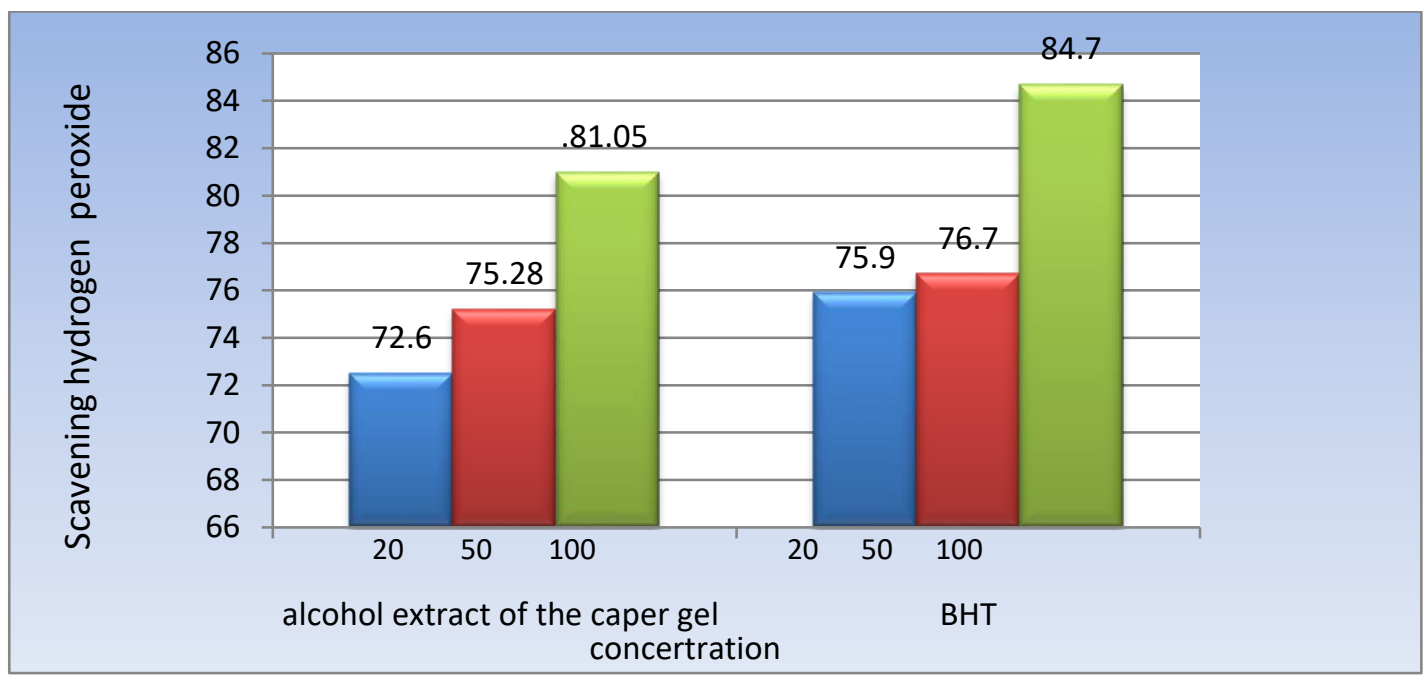

RLSD for concentrations $=\mathbf{2 . 0 5}$

Fig. (3):The ability of the caper alcoholic extract gel to scavenging hydrogen peroxide

\section{Ferrous ion chelating}

Fig. (4). showed that the ability of the caper gel alcoholic extract to chelate ferrous ion was highly significant $(P<0.01)$ compared to EDTA (Ethylene diaminetetraacetic acid). Increasing the extract concentration increased chelating ability $(74.53 \%$ at $20 \%$ concentration, $87.07 \%$ at $50 \%$ concentration and $89.52 \%$ at 100 concentrations).
The chelating capacity of EDTA was 85.39 $\%, 91.83 \%$ and $93.15 \%$ at the same concentrations, respectively. The ability of the alcoholic extract to chelate ferrous ion was the effective compounds that have a high ability to bind metals (Nagulendran et al. 2009). 
Al-Birawee \& Nasser / Basrah J. Agric. Sci., 32 (2): 77-87, 2019

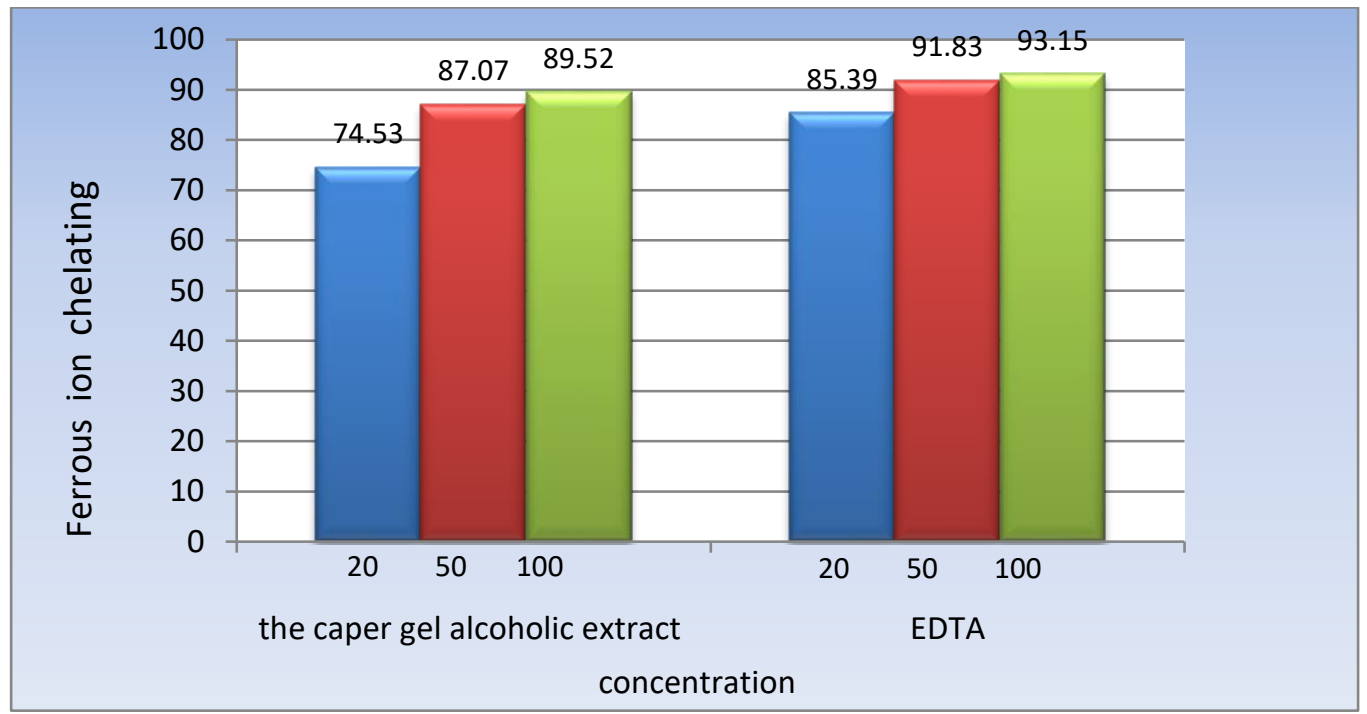

RLSD for concentrations $=\mathbf{2 . 5 5}$

Fig. (4): The ability of alcohol extract of caper gel to ferrous ion chelating

\section{Conclusions}

The extraction of gel from caper fruits was possible. Caper gel contains active compounds such as phenols, alkaloids, resins, and flavonoids. No significant differences between caper gel and synthetic antioxidants were observed.

\section{Acknowledgment}

I would like to thank everyone who helped me to complete this research, I would like to mention Prof. Dr. Asaad Y. Ayied from Department of Animal Production, College of Agriculture, University of Basrah for his help in statistical analysis.

\section{Conflicts of interest}

The authors declare that they have no conflict of interests.

\section{References}

A.O.A.C. (2000). Official Method of Analysis. Horwitz, W.L.; George W. \& Latimer. Jr. (Eds.). 18th ed. Washington,
D.C., Association of official Agricultural Chemists: 2200pp.

Al-Jubouri, A.H.; Abadi, I.M. \& Shaker, K.A.R. (2014). Extract of flax seeds from Linum usitatissimum L. cultivated in Iraq. J. Coll. Sci. Al-Nahrain Univ., 17(3): 4149. (In Arabic).

Al-Khazaraji, S.M. (1991). Biopharmacolog-. ical study of Artemisia herba, M. Sc. Thesis, Coll. Pharm. Univ. Baghdad: 124pp.

Al-Moussawi, A.H.J. \& Al-Halfi, S.A.H. (2012). Separation, diagnosis, and evaluation of the antioxidant activity of phenolic compounds of some plant extracts. J. Univ. Karbala. $2^{\text {nd }}$ Sci. Conf. Fac. Agric.: 1218-1228. (In Arabic).

Al-Rawi, K.M. \& Khalaf Allah, A.A.M. (2000). Design and Analysis of Agricultural Experiments. Second Edition, House of Books for Printing and Publishing, Univ. Mosul: 488pp (In Arabic). 
Ashour, E.A.; Alagawany, M.; Reda, F.M.; Abd El-Hack, M.E.; Abaza, I.M.; El-Said, H.; Acamovic, T.; Brooker, J.D.; Aebi, H.; Al-Bar, A. \& Cheeke, P.R. (2005). Association of official analytical chemists official methods of analysis. Asian. J. Anim. Vet. Adv., 9(11): 259-266.

Bhaduri, S. (2016). An assessment of antioxidant and antiproliferative activities of super grain quinoa. J. Food. Process. Techn., 7(2): 107-109.

Chaudhary, G.; Goyal, S. \& Poonia, P. (2010). Lawsoniainermis Linnaeus: A phytopharma ecological review. Int. J. Pharm. Sci. Drug Res.; 2(2): 91-98

Comai, S.; Bertazzo, A. \& Bailoni, L. (2007). The content of protein and non-proteic (Free and Protein-Bound) tryptophan in quinoa and cereal flours. Food Chem., 100: 1350-1355.

Dickinson, E. (2003). Hydrocolloids at interfaces and the influence on the properties of dispersed systems. Food Hydrocolloids, 17(1): 25-39.

Fekri, N.; Khayami, M.; Heidari, R. \& Jamee, R. (2008). Chemical analysis of flaxseed, sweet basil, dragon head, and quince seed mucilages. Res. J. Biol. Sci., 3(2): 166170.

Garti, N. \& Leser, M.E. (2001). Emulsification properties of hydrocolloids. Polymers Adv. Technologies, 12: 123-135.

Goycoolea, F.M. \& Cárdenas, A. (2003). Pectins from Opuntia spp.: A short review. J. Prof. Assoc. Cactus Dev., 5(1): 17-29.

Gülçın, İ.; Oktay, M.; Kıreçc1, E. \& Küfrevığlu, Ö.İ. (2003). Screening of antioxidant and antimicrobial activities of anise (Pimpinella anisum L.) seed extracts. Food Chem., 83(3): 371-382.

Gunjan, M.; Naing, T.W.; Saini, R.S.; Ahmad, A.; Naidu, J.R. \& Kumar, I. (2015). Marketing trends and future prospects of herbal medicine in the treatment of various diseases. World J. Pharm. Res., 4(9): 132-155.

Harborne, J.B. (1984). Phytochemical Methods: A Guide to Modern Techniques of Plant Analysis. Springer, Dordrecht London: 288pp.

Hosseini-Parvar, S.H.; Matia-Merino, L.; Goh, K.K.T. \& Mortazavi, S.A. (2010). Steady shear flow behavior of gum extracted from Ocimum basilicum L. seed: Effect of concentration and temperature. J. Food Eng., 101: 236-243.

Khaled, F.A.; Yousef, M.I. \& Kamel, K.I. (2016). The protective role of propolis against the reproductive toxicity of monosodium glutamine in male rabbits. IJCS, 4(2): 4-9.

Kim, S.; Choung, S. \& Hyun, S. (2006). Antidiabetic effect of cinnamon extract on blood glucose in $\mathrm{db} / \mathrm{db}$ mice. $\mathrm{J}$. Ethnopharmacol., 104: 119-123.

Ma, Z.F. \& Zhang, H. (2017). Phytochemical constituents, health benefits, and industrial applications of grape seeds: A minireview. Antioxidants, 6(3): 71. doi:10.3390/antiox 6030071.

Manhiani, P.S.; Northcutt, J.K.; Han, I.; Bridges, W.C. \& Dawson, P.L. (2013). Antioxidant activity of carnosine extracted from various poultry tissues. Poult. Sci., 92 (2): 444-453.

Nagulendran, K.R.; Velavn, S.; Mahesh, R. \& Begum, V.H. (2009). In vitro antioxidant 
activity and total polyphenolic content Cyperusratundus rhizomes. J. Chem., 4: 440-449.

Osawa, T. \& Namiki, M. (1981). A novel type of antioxidant isolated from leaf wax of Eucalyptus leaves. Agric. Biol. Chem., 45: 735-739.

Pascual, B.; San Bautista, A.; Lopez-Galarza, S.; Alagarda, J. \& Maroto, J.V. (2006). The intact fruit of Caper (Capparis spinosa) is an improved seed propagation method. Acta Hortic., 782: 107-114

Razavi, S.M.A.; Mortazavi, S.A.; MatiaMerino, L.; Hosseini-Parvar, S.H.; Motamed Zadegan, A. \& Khanipour, E. (2009). Optimization study of gum extraction from basil seeds (Ocimum basilicum L.). Int. J. Food Sci. Techn., 44: 1755-176.

Singer, F.A.W.; Taha, F.S.; Mohamed, S.S.; Gibriel, A. \& El-Nawawy, M. (2011). Preparation of mucilage/protein products from flaxseed. Am. J. Food Technol., 6(4): 260-278.
SPSS. (2012). Statistical Packages of Social Sciences. Version 15 for Windows. SPSS. Inc.

Tesoriere, L.; Butera, D.; Gentile, C. \& Livrea, M.A. (2007). Bioactive components of Caper (Capparis spinosa L.) from Sicily and antioxidant effects in a red meat simulated gastric digestion. J. Agric. Food Chem., 55: 8465-8471.

Türkoğlu, S.; Çelik, S.; Türkoğlu, Đ.; Çakılcığlu, U. \& Bahsi, M. (2010). Determination of the antioxidant properties of ethanol and water extracts from different parts of Teucriumparvi florum Schreber. Afr. J. Biotechnol., 9(40): 67976805.

Yasser, M.H. (2011). Effect of Capparis spinosa leaf extracts on the growth of Fusarium oxysporum and Rhizoctonia solani isolated from Citrullus watermelon. J. Thi-Qar Sci., 2 (4): 71-83

Zia-Ul-Haq, M.; Ćavar, S.; Qayum, M.; Imran, I. \& Feo, V.D. (2011). Compositional studies: antioxidant and antidiabetic activities of Capparis decidua (Forsk.) Edgew. Int. J. Mol. Sci., 12(12): 8846-8861 